Complex uses of an

\section{advanced tool}

Quantitative Scanning Electron Microscopy. Edited by D. B. Holt, M. D. Muir, P. R. Grant and I. M. Boswarva. Pp. $\mathrm{X}+570$. (Academic: London and New York, January 1975.) £15.50.

SINCE the early 1960s, the accessibility of the scanning electron microscope (SEM) as a working tool in the hands of scientists has grown tremendously. For example, just one of the several SEM manufacturing companies lists over 500 owners throughout the world, which may imply 10 times as many users. Furthermore, a lot of ingenuity has gone into finding new uses for a tool which yields dramatic topographical pictures suitable for hanging on the wall but can also probe the basic electrical and crystallographic properties of materials in many more subtle ways. This book attempts to review the unique methods by which the properties of inorganic materials may be measured quantitatively using the interaction of a rastered kilovolt electron beam with a solid. It explicitly avoids an introductory approach, but, as parts of it evolved from a lecture course, it is well adapted for an advanced teaching course.
Fifteen authors, mainly from British universities, gave authoritative reviews of each use of the SEM and a strong quadripartite editorial team has successfully imposed unity on the contributions, keeping a sharp eye on the possible future development of the instrument. Several aspects of the production of finer and better controlled electron beams occupy the first three chapters, including an unusual and useful review of the very complicated interaction of electrons with solids and a rather casual run through "the approach to $1 \AA$ " by the renowned Albert Crewe. Six chapters on the quantitative interpretation of contrast borrow from and build upon the art developed for the transmission electron microscope (TEM). Howie's chapter does this by means of a unified survey of diffraction contrast and scattering in the TEM mode (including the scanning and glancing-angle modes) and the backscattering mode.

The emissive mode, for all its importance, is compressed efficiently by Gopinath into only 30 pages, but it would not have been too much of a diversion for the editors to have inserted a chapter on the morphology and physics of crystalline organic materials, thereby capturing a large additional readership.

Finally, the versatility of the SEM is suitably revealed in the section on the use of the X-ray yield of the SEM sample. This section again gives prominence to creative, forward-looking aspects and, indeed, the final chapter on automatic stereological analysis by Jones indicates that a strong use of the imagination and the help of a computer can tell one what is in the bulk of a mineral conglomerate, working only from the surface X-ray energy analysis. The greatest lack I noticed was of any discussion of the positive side of electron beam damage such as is observed with kilovolt electrons on films of alkali halides. In fact, the editors have stuck rather narrowly to the technologically useful metals, semiconductors and phosphors and the emission therefrom.

This book is not a handbook; I regret somewhat the lack of survey tables and appendices. In general, the editors have not pressed their authors to prepare the information better for their readers. Diagrams are redrawn from the research literature rather than pulled apart, condensed and recombined for clarity. The subediting on diagrams is sometimes loose as to symbols and captions, which may cause the neophyte some crises of confidence. These minor points aside, this is a book which the novice microscopist having grasped the basic principles elsewhere, can use with confidence as a guide to the complex uses of the SEM.

Andrew Holmes-Siedle

\section{Maternal lifeline} to

\section{foetus}

The Placenta and its Maternal Supply Line: Effects of Insufficiency on the Fetus. Edited by P. Gruenwald. Pp. $\mathrm{x}+$ 366. (MTP: Lancaster, April 1975.) $£ 11.50$.

THE declining perinatal mortality in developed countries has highlighted the importance of foetal subnutrition in utero as an increasingly common cause of perinatal morbidity and mortality. The present volume is therefore well timed and provides a useful summary of current theories concerning the physiology of foetal growth and possible therapeutic approaches to suboptimal growth patterns in utero. Professor Gruenwald has a distinguished record in this area, and was one of the first workers to stress the difference between infants of low birth weight due to premature delivery and those due to intrauterine growth retardation. The volume consists of chapters written by a variety of contributors-usually research workers with a particular interest in the subject-and there is therefore no uniform style. Many of the chapters are well illustrated, whereas some have no illustrations at all. The illustrations used by the editor tend to be complicated and difficult to interpret at a glance. The majority of authors present an objective view of their subject but in some cases the author's own viewpoint is emphasised with only cursory reference to opposing schools of thought. The book is well referenced and the bibliography is extensive.

On balance the volume presents a comprehensive review of the current literature on placental development and pathophysiology, as well as a shorter section on foetal growth and pathophysiology, not only in human but in other species. The authors emphasise certain areas in which further research is needed, and particularly the need for new diagnostic and therapeutic possibilities in pregnancy. At $£ 11.50$ the volume is recommended as a valuable addition to every medical and biological sciences library as well as to interested investigators.

\section{ПЕРЕВОДИИКИ!}

\section{FOR RUSSIAN-ENGLISH SCIENTIFIC AND TECHNICAL TRANSLATIONS}

You can follow the latest Soviet research in your field, and supplement your income, by translating in your home on a free-lance basis. If you have a native command of English, a good knowledge of Russian, and experience or academic training in a scientific or technical discipline, you may be qualified for our translation program. Immediate openings are available in physics, materials science, geology and biomedical, civil, environmental and chemical engineering, as well as other fields. With our constantly expanding program, we can guarantee you a continuous flow of translations in your specialty.

For additional information contact:

Translations Editor

Plenum Publishing Corporation

227 West 17th Street, New York, N.Y. 10011 